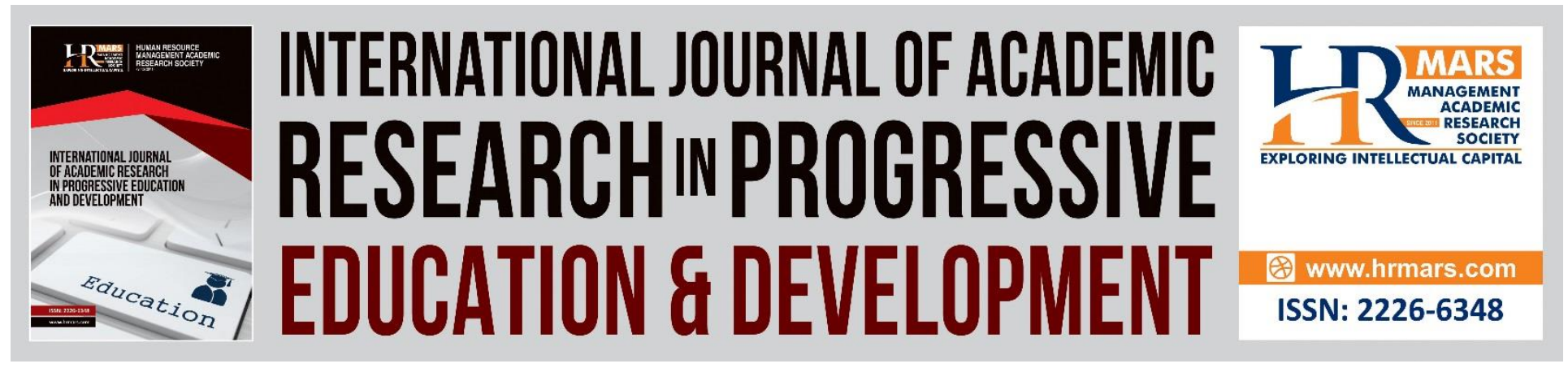

\title{
Developing and Validating Malay Instrumental Music Method Book for Novice's Music Educators
}

Mahayuddin Abdul Rahim, Mohd Nizam Nasrifan, Zaharul Lailiddin Saidon

To Link this Article: http://dx.doi.org/10.6007/IJARPED/v9-i2/7485

DOI:10.6007/IJARPED/v9-i2/7485

Received: 18 March 2020, Revised: 20 April 2020, Accepted: 17 May 2020

Published Online: 26 June 2020

In-Text Citation: (Rahim \& Saidon, 2020)

To Cite this Article: Rahim, M. A. M. N. N., \& Saidon, Z. L. (2020). Developing and Validating Malay Instrumental Music Method Book for Novice's Music Educators. International Journal of Academic Research in Progressive Education and Development, 9(2), 432-439.

Copyright: (C) 2020 The Author(s)

Published by Human Resource Management Academic Research Society (www.hrmars.com)

This article is published under the Creative Commons Attribution (CC BY 4.0) license. Anyone may reproduce, distribute, translate and create derivative works of this article (for both commercial and non-commercial purposes), subject to full attribution to the original publication and authors. The full terms of this license may be seen at: http://creativecommons.org/licences/by/4.0/legalcode

\section{Vol. 9(2) 2020, Pg. 432 - 439}

Full Terms \& Conditions of access and use can be found at http://hrmars.com/index.php/pages/detail/publication-ethics 


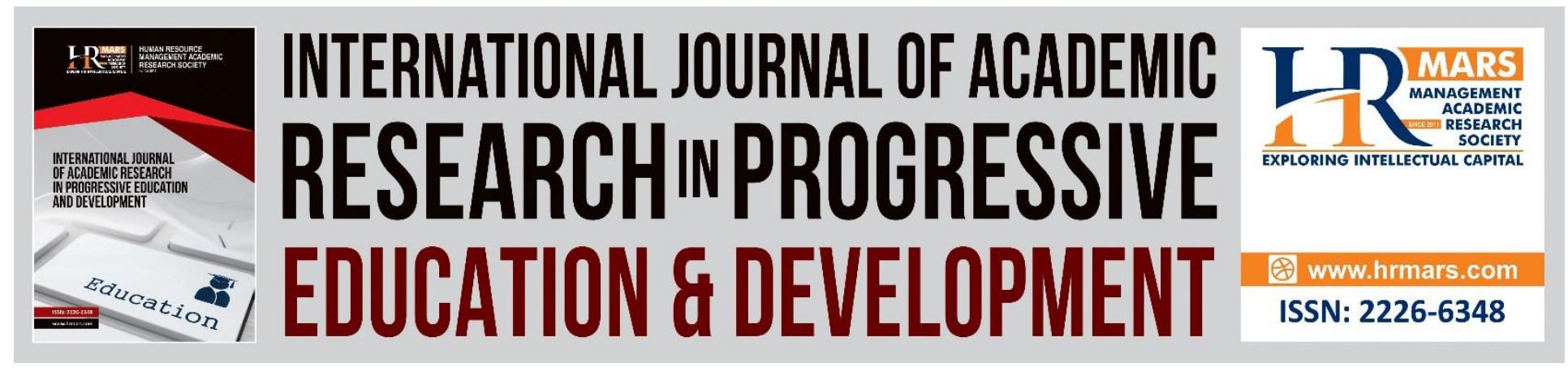

\title{
Developing and Validating Malay Instrumental Music Method Book for Novice's Music Educators
}

\author{
Mahayuddin Abdul Rahim, Mohd Nizam Nasrifan, Zaharul \\ Lailiddin Saidon
}

Music Department, Faculty of Music and Performing Arts, Universiti Pendidikan Sultan Idris, 35900 Tg Malim, Perak, Malaysia.

\begin{abstract}
This study aims to develop a Malay instrumental music method book featuring systematic rehearsal techniques and Malay traditional folk songs. The main objective is to assist novice music teachers in conducting music ensembles such as the wind orchestra with a systematic approach. The early studies revealed that most novice music teachers are not confident in handling the wind orchestra due to a lack of training and experience. Some music teachers used method books for ensemble music teaching but, without systematic rehearsal techniques. Moreover, most of the songs are western folk songs, and there is not a single method book written in Malay. Data from interviews, observations, and documentation of the respondent verify that rehearsal etiquette, rehearsal techniques, singing, and performing musical and technical exercises; warmup exercises are considered fundamentals in teaching instrumental music and introduced in the method book. The engagement of the Malay folk songs manages to capture the interest of students learning music. At the same time, it increases musical understanding, interpretation, and expression of teachers and student musicians. All respondents agree that the Malay method books cover fundamentals instrumental music teaching importantly for novice music teachers. However, the results of the study are from limited respondents. Therefore, it cannot be generalized though, it might be useful for local music teachers in Malaysia and to anyone confronting a similar phenomenon.

Keywords: Malay Instrumental Method Book, Systematic Rehearsal Techniques, Rehearsal Etiquette, Novice Music Teachers, Malay Folk Songs.

\section{Introduction}

Most music teachers in Malaysia illustrate unconvincing rehearsal techniques in teaching music ensemble compared to professional music instructors. Pearson (2018) wrote, "A good rehearsal starts with a good teacher. In other words, the educational attitude that is reflected on the podium will have a tremendous effect on the success or failure of the conductor rehearsal time" (pp. 1). The lack of training and experience in ensemble music teaching is undeniable. The ineffective teaching models among preservice teachers are displaying insufficient rehearsal
\end{abstract}


techniques, which is fundamental in teaching instrumental music ensembles (Berz, 2005; Crawford, 2000; Hinton, 2008; Johnson, 2007; Lane, 2004; Woody, 2002, 2006). Still, the local communities expected them to conduct the wind orchestra or the marching band at its highest level.

An earlier investigation shows that local Band instructors use western music method books as a reference in their instrumental music teaching. Besides, there is not a single music method book (orchestra) written in the Malay language. The method books are in English with western traditional folk songs and without instructions for systematic rehearsal techniques, which is crucial for novice music teachers. It creates extra challenges for the novice music teachers to display systematic rehearsal techniques and to incorporate local music, culture, and heritage to the teaching and learning proses. Carl Orff, Dal Cruz, Suzuki, and Kodaly (n.d) emphasize that the use of local folk and traditional songs is to enhance meaningful music learning.

This study implements a qualitative research method that emphasizes interviews, observations, and documentation with five respondents that have strong engagement in teaching and learning instrumental music. Results from the finding revealed that the method book includes fundamentals in teaching instrumental music. The book provides systematic rehearsal techniques, rehearsal etiquette, breathing exercises, tuning, warm-up exercises, rhythm studies, articulations, scales, harmony, blend, and balance. Besides, the four Malay folk songs may increase students' understanding, interpretation, and expression, of the song, which lead them to having an interest in local music and culture.

\section{Problem Statements}

Teaching and learning through performance is an efficient way of teaching and learning music. However, local music teachers in Malaysia need adequate training and experience in conducting sizeable instrumental music ensembles in systematic teaching strategies. Besides teaching music, music teachers are required to prepare music arrangements, rehearsal planning, teaching different subjects, and are attached to school activities.

Teaching and learning through performance is an efficient way of teaching and learning music. However, local music teachers in Malaysia need adequate training and experience in conducting sizeable instrumental music ensembles in systematic teaching strategies. Besides teaching music, music teachers are required to prepare music arrangements, rehearsal planning, teaching different subjects, and are attached to school activities. Furthermore, published method books were in the English language that incorporates with western folk songs, making it more complicated for the local music teachers to engage student's musicians with local music, culture, and heritage. Besides, local folks and traditional songs were suggested by music educators for expressive interpretations and meaningful music learning. Furthermore, there is not a single music method book written in the Malay language. Therefore, the research aims to develop a Malay language method book for novice music teachers while engaging the Malay traditional and folk songs with systematic rehearsal teaching techniques. 


\section{Research Methodology}

This qualitative research aims to develop a Malay language instrumental method book that applies systematic rehearsal techniques and procedure while portraying the Malay traditional and folk songs. Data collection in its natural setting enables the researchers to investigate and observe what are the fundamentals of teaching instrumental music ensembles (Stake, 1995; Yin 2009). Band instructors, a novice music teacher, two student musicians, and one instrumental music professor has agreed to involve as the respondent. All respondents have actively involved in instrumental music teaching and learning. The main purpose of the study, which was to exaggerate the perception and understanding of the phenomenon but not to accomplish population validity. Furthermore, it is a natural practice in most research to utilize participants who are manageable to be administered by the researcher (Gall, Gall, \& Borg, 2007).

Gall et al. (2007) stated that researchers should focus on a single phenomenon at a time, studying it with appropriate procedures, instruments, data collection, and analysis. The researchers conducted eight semi-structured interviews, eight, and collect documents from selected respondents. However, some interview was conducted through telephone calls and in places agreed by both parties. The research process includes applying research ethics and procedures. The researcher uses the interview protocol containing semi-structured interviews and open-ended questions that recalled the observations researcher's attention for accurate data collection for the study (Miles \& Huberman, 1994).

Data from all samples were carefully analyzed, categorized, and transcribe. The process enables the researcher to choose and establish rehearsal techniques that are crucial to novice music educators and was introduce in the Malay instrumental music book. Four local music arrangers organized and arrange the music exercises and rearrange the Malay folk songs with guidance from the researcher's purposes. All four songs were arranged by different arrangers in a wind orchestra setting and highlight different music styles and tempo.

The researcher provides a draft of the Malay method book to all five respondents to collect and gather data regarding their feedback and validation on the method book. However, the local high school music teacher and members of the orchestra has to study the Malay method book, practice, rehearsed, and need to perform one of the arrangement. Feedbacks from all respondents and student musicians were critically analyzed and has contributed towards improving the method book.

\section{Research Results}

Research question 1 aims to investigate what are the skill, knowledge, activities, and practices required in the Malay method book.

The research result showed that musicians ethic, rehearsal techniques, and procedures are crucial for novice music teachers. Despite that, fundamental in music theory and practical is a must before establishing advanced music skills and knowledge. Data from the research showed that teaching and learning activities such as stretching, warmup, and systematic rehearsal techniques are crucial in assisting novice music teachers and student musicians for better music understanding and skill. According to the instrumental music professor, "not all students are capable of developing their skills in a short period. Mostly embouchure and tone ...that is why 
warmup exercises have remains as a routine in every rehearsal. However, the main concern is to get things properly organized and interesting to students".

Musical elements such as tempo, note values, rhythm pattern, tone, articulations, expression, blend, and balancing should be the main focus in most activities and all the skills needed for producing good music". According to band instructors, simple stretching activities with music background helps student's physical and mental readiness and alertness. It also helps students to develop alertness in tempo..." Therefore "it is wise to use instrumental music with different style, tempo, and ensembles". The instructor also mentioned that stretching activities with music are important "we instructors should guide them... importantly on the accuracy of their tempo, which is observable through the sharpness of their movements and sound," The instrumental music professor mentioned that "Simple stretching will only take a few minutes... students should take serious with it...do it properly motivates students to express stretching movement with the music background....".

Breathing is fundamental in developing good embouchure and tone production for wind musicians. All research samples agree that breathing techniques will enable wind musicians to construct good embouchure that leads to good tone production. Instructors need to explain and demonstrate correct breathing techniques. Practicing correct breathing is a challenging task. The instructor mentioned that creative movements and seriousness in teaching would help in controlling student's attitudes. According to the instructor, He went around his students to check and to correct their breathing techniques, embouchure, and mouthpiece placement during the warmup session to assure that every musician is doing it correctly.

Moreover, playing soft tone with warm and higher pitch may produce a better result on range and tones". The band instructor illustrated some creative movements called breathing gyms. He learned it through videos from the internet. However, proper instructions are crucial for better results, for example, the bow and arrow technique whereby students inhale during pulling the arrow and exhale according to the speed when releasing the arrow. Data from observations showed that band instructors and instrumental music professors demonstrated several kinds off breathing techniques and explained the purposes of each activity. Students' voices, facial gestures, and body movements illustrated and justified their enjoyment in doing the activities.

Rehearsal techniques were observed in its real setting and were conducted by a well know school Band instructor and a professor from the local Malaysian university. Both the school and the university portrayed systematic rehearsal techniques. Checking of attendance, stretching, and breathing exercises were well established in the early stage of every rehearsal. Section leaders lead the tuning during sectional practice. Playing a long tone of several notes on the mouthpiece and their instruments accurse to be the first steps before tuning the instruments. However, some senior students managed to tune their instruments without using the tuner and can assist other members in tuning the instruments.

Sectional practice begins by dividing the whole group according to instruments, senior, and junior members. The junior musicians were mostly beginners that need more attention towards developing necessary skills such as mouthpiece placement, embouchure, posture, fingering, tone, pitching, notes, and rhythm. At the same time, the senior groups focus more on music interpretations and expressions of the performance pieces. The section leaders assist their 
group for better music interpretation. They manage to detect, demonstrate, and correct musical errors on tone, blend, balancing, harmony, articulations, and phrasing. The sectional practice continues about an hour before combining the whole section in a group.

All sections combine as a complete wind orchestra. The Band instructor conducted the session, starting with a few instructions, motivation, tuning, scales, rhythm patterns, and warmup piece before playing the performance pieces. The Band instructor was able to pledge for better tone, blend, rhythm balancing, harmony, articulations phrasing, and managed to established expressive music performance during basic exercises and the performed music.

Both the Band instructors and the instrumental music professor displayed similar action during rehearsal. They give specific attention to tempo, tuning, tone, pitching, tonguing, range, lips flexibilities, and other musical elements. It makes the performance sounded lively. Musical mistakes were carefully notified and guided during and after performance using verbal and nonverbal instructions. They were very skillful, detailed, and manage to correct musical errors in short and accurate guidance.

According to the Band instructor, some students have difficulties in their performance; despite immediate corrections, he chooses to consult with them after rehearsal and save more rehearsal time. Moreover, it provides better results. One of the student musician states, "I think the instructor is trying very hard to help us...he made us think and understand our performance problem...so I should try my best to deliver the music..." Data from the research allowed the researchers to analyzed and choose relevant practices for the Malay instrumental method books. The instrumental music professor mentioned that there are many rehearsal etiquette, rehearsal warm-up, and coral in the internet. Some of them are free and ready to use. Mc Allister Symphonic warm-up is one of the good example.

Research question 2 investigates experts respond (validation) to the Malay instrumental music method book.

The Malay method book that we developed consists of fundamentals instructions on rehearsal ethics, rehearsal techniques, warmup exercises, and exercises align with all the four Malay folk songs. The high school Band instructor and instrumental music professor suggested some tips regarding the musician ethic and procedure. They believed that the book could assist novice music teachers in practicing systematic rehearsal techniques.

The Band instructor stated that the exercises for all four songs were well synchronized and should be able to save more rehearsal time. At the same time, the instrumental music professor mentioned that all the exercises are crucial in developing individuals playing skills, and the checklist for rehearsal ethic is appealing. The Band instructor and the instrumental music professor mentioned that the book covers most of the fundamental in teaching instrumental ensembles and is useful for novice music teachers.

Research Question 3 aims to reveal significant changes displayed by the novice music teacher after using the Malay method book.

The researcher presents the Malay method book to a novice music teacher who is also a Band instructor in a secondary school. He studied the book a week before rehearsing it in his wind orchestra. The novice music teacher does not have a severe hurdle of implementing all the procedures and exercises as proposed. He manages to displayed the stretching, breathing, 
rhythm studies, scales, and all exercises confidently. He stresses the importance of doing those exercises and leads to students' interest in his instructions.

In the fourth week observation, members of the orchestra have displayed superb improvements in their ethic and performance. They looked and act like professional musicians and were able to perform the music with better tones. Surprisingly, most of the student musicians perform the music and all musical exercises with credible expression. The novice music teacher displayed firm and confident teaching and did not have any difficulties in applying the instructions and exercises from the method book. The teacher's explanations and modeling of the exercises, musician ethic, and rehearsal technique justified the effectiveness of the guidelines in the method book. The music teachers practice the systematic rehearsal technique as in the method book. He leads his student's musicians to sing, buzz, and played the exercises with proper techniques and procedures.

In week eight, the novice teacher succeeded in displaying positive changes in his students' behavior and performance during rehearsals and performance. It has justified the effectiveness of the musicians' ethics introduces in the method book. Moreover, the song and music arrangement manage to capture students' interest. According to the novice music teacher, the students enjoy playing the folk song in the method book. Student musician's body movements, facial gestures, and credible expressions displayed during their performance reveal their understanding of the musical interpretation of the songs.

Musical elements such as tone, tempo, not values, and music articulations were well developed. Most of the student musicians manage to produce a beautiful tone compare to before. The orchestra sounded much better.

Conversely, the novice music teacher suggested recording arrangements of the song for better music interpretations and expression. He also suggested more materials written in the Malay language, such as advance rehearsal exercises and intermediate levels of local song arrangements.

\section{Discussion and Conclusion}

Experience in conducting a big orchestra is a very challenging task for novice music teachers. Hence, novice music teachers need to encounter professional assistance before they could establish proper instructions, interpretation, and expressiveness of the music. This method book is for novice music teachers. Therefore, Instrumental music rehearsal, rehearsal ethic, and basic musical exercises are crucial. For that purpose, the musician's ethic, symphonic warm-up routine, and individual practices aligned with each song in the method book. Data from the research showed that the method book is handy for novice teachers and able to helps improve novice music teacher's skills and knowledge in conducting instrumental music ensembles. Biggs et al., as cited in Mahayuddin (2013) "displaying a high level of student musicianship," and "being knowledgeable about participant matter materials were the most necessary skills in being able to "motivate students" and "maintain excellent classroom management and procedures" (p.17). However, the findings were from limited research subjects. Therefore, the result of this study may not necessarily apply to all novice music educators, though the effect has substantial implications for local music teachers and students. Furthermore, developing knowledge and skill among novice music educators is applicable through other perspectives. Future researchers can 
Vol. 9, No. 2, 2020, E-ISSN: 2226-6348 C 2020 HRMARS

apply mentoring, professional developments, conducting skills, teaching skills, education, and teaching strategies which, might also influence the music program, teacher training program, and as well as performance of the instrumental music ensemble.

\section{Acknowledgement}

This article is based on research project from the "PENYELIDIKAN KHAS UNIVERSITI BERTERASKAN PENDIDIKAN", code 2017-0237-107-01. Title: Developing and Evaluating Malay Instrumental Music Method Book for Novice Music Teachers funded by Research Management Innovation Centre (RMIC), Universiti Pendidikan Sultan Idris.

\section{Corresponding Author}

Mahayuddin Abdul Rahim

Senior Lecturer, Music Department, Faculty of Music and Performing Arts, Sultan Idris Education University, (UPSI) Malaysia

Email: mahayuddin@fmsp.upsi.edu.my

\section{References}

Berz, W. (2005). Defining performance standards. Tempo, 59(4), 72-73.

Crawford, L. (2000). General music 10-20-30. Guide to implementation, Alberta Learning and Teaching Resources Branch: Edmonton, Canada.

Gall, M. D., Gall, J. P., \& Borg, W. R. (2007). Educational research (8th ed). New York, NY: Pearson.

Hinton, E. L. (2008). Conducting the wind orchestra: Meaning, gesture and expressive potential. Amherst, NY: Cambria Press.

Johnson, R. G. (2007). What's new in pedagogy research? Discussion of "The effect of various instructional conditions on expressive music performance" by Robert Woody". The American Music Teacher, 56(4) 70-1.

Lane, J. S. (2004). A basic interpretive analysis of undergraduate instrumental music education majors approaches to score study in varying musical contexts. (Unpublished doctoral dissertation). Louisiana State University, Baton Rouge, LA.

Mahayuddin, A. R. (2013). A Case Study of Mentoring a Student Teacher in Instrumental Ensemble Conducting with an Emphasis on Interpretation and Expressivity. (Unpublished doctoral dissertation, Nova Southeastern University, Davie, Florida).

Miles, M. B., \& Huberman, A. M. (1994). Qualitative data analysis: An expanded source book (2nd ed.). Thousand Oaks, CA: Sage Publications.

Pearson, B. (2018). Rehearsing the Very Young Band - Part One. Retrieve Feb 16. 2020 from http://brucepearsonmusic.com/wp-content/uploads/2018/08/Rehearsing TheVeryYoungBand_Pt1.pdf

Stake, R. K. (1995). The art of case study research. Thousand Oaks, CA: Sage.

Woody, R. H. (2002). Emotion, imagery and metaphor in the acquisition of musical performance skill. Music Education Research. 4(2), 213-224.

Woody, R. H. (2006). The effect of various instructional conditions on expressive music performance. Journal of Research in Music Education, 54(1), 21-36.

Yin, R. K. (2009). Case study research: Design and methods (4th ed.). California: SagePublications. 